\title{
Exploration Of The Relationship Between LMX And Demographic Variables
}

\author{
Connie B. Green, (Email: GreenC@uiwtx,edu), University of the Incarnate Word \\ Annette E. Craven, (Email: Craven@uiwtx.edu), University of the Incarnate Word \\ Jeannie Scott, (Email: Scott@uiwtx.edu), University of the Incarnate Word \\ Lorena G. Gonzales, Our Lady of the Lake University
}

\begin{abstract}
This study of 143 participants from an international company examined the relationship between LMX and demographic variables. LMX results represent the quality of the dyadic relationship between leader and follower. Demographic variables included age, gender, education and organizational tenure. Study results suggest significant findings between education and LMX results at the follower level.
\end{abstract}

\section{INTRODUCTION}

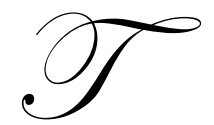

he purpose of this study was to examine the relationship between the quality of dyadic exchanges between leader and follower and the demographic variables of age, gender, education, and organizational tenure. The study sample included office administrators, human resource administrators, accounts receivable champions, total service managers, and general managers employed by an international company with 160 offices across the continental United States.

This introduction provides background on the quality of exchanges between leader and follower, placing the research question into context. It presents the lack of research specifically addressing the relationship between the quality of the relationship between leader and follower and the demographic variables: age, gender, education, and organizational tenure.

Effective leadership is critical to organizational success. Leadership is defined by Northouse (2001) as a process, specifically as the "...process whereby an individual influences a group of individuals to achieve a common goal" (p. 11). This process is not a unidirectional relationship but a multidirectional one supported by both leader and follower. The topic of leadership has gained much contemporary appeal in both the practitioner and scholar arenas however it is a complex concept, the nature of which is lacking consistent agreement among practitioners and scholars. It is this complexity that provides challenge to practitioners and scholars alike. As Northouse (2001) stated: "Because leaders and followers are both part of the leadership process, it is important to address issues that confront followers as well as those that confront leaders. Leaders and followers need to be understood in relation to each other." (p. 11)

The primary goal of for-profit organizations is the maximization of shareholder wealth (Brighton \& Houston, 2004; Ross, Westerfield, \& Jaffe, 2002). Harter, Schmidt, and Hayes (2002) conducted a meta-analysis of the relationships among employee satisfaction, employee engagement, and business outcomes. The results of this study suggested "...that employee satisfaction and engagement are related to meaningful business outcomes at a magnitude that is important to many organizations and that these correlations generalize across companies" (p. 15). The implication from such studies is that increasing follower job satisfaction may lead to an increase in job performance, ultimately resulting in greater organizational effectiveness.

Results of studies by Graen and Uhl-Bien (1995), Graen, Novak, and Sommerkamp (1982), and Graen and Scandura (1987) suggested that productivity increases as the quality of the leader-member exchange increases. Graen, 
Novak, and Sommerkamp (1982) suggested "...the exchange of help and support (from the leaders) for the commitment to improve performance (by the follower) will result in higher follower performance" (p. 129). Key to these studies is the concept of an exchange between leader and follower.

Leader-member exchange, affects organizational effectiveness; however, there is a lack of research supporting or specifically addressing the relationship of the quality of dyadic exchanges between leader and follower and age, gender, education, and organizational tenure. This study examined this relationship, seeking to add to a limited body of knowledge.

Therefore, the purpose of the study was to examine the relationship between leader-member exchange and demographic variables: age, gender, education, and organizational tenure. The primary null hypothesis for this study was: $\mathrm{H}_{01}$ : there is no relationship between the quality of dyadic relationship between leader and follower and the demographic variables of age, gender, education, and organizational tenure.

Participants were selected by the vice president of human resources for this international company and were limited to current U.S. employees. This study was limited to one company; therefore limiting the researcher's ability to generalize study findings. This study focused on correlational data and made no attempt to address the cause and effect issues related to leader-member exchange or leadership.

\section{REVIEW OF THE LITERATURE}

\section{Leadership Theory}

Leadership is “...a process whereby an individual influences a group of individuals to achieve a common goal" (Northouse, 2001, p. 3). There are numerous and varied classifications of leadership theories. In the interest of providing a brief historical framework, leadership approaches have been classified into seven primary leadership theories: (a) trait, (b) style, (c) situational, (d) contingency, (e) path-goal, (f) transformational, and (g) leader-member exchange.

Trait theories focus on the actual traits and characteristics of leaders, not on leadership as a process. "These theories were developed and were called 'great man' theories because they focused on identifying the innate qualities and characteristics possessed by great social, political, and military leaders" (Northouse, 2001, p. 15). Leaders share traits such as "...intelligence, self-confidence, determination, integrity, and sociability" (Northouse, 2001, p. 19). Lussier (2003) "...focus on the jobs and structure of the firm" (p. 35). Additional theorists associated with classical approaches include Taylor, Fayol, Weber, and Follett (Boone \& Bowen, 1987).

Style theories “...provide a framework for assessing leadership in broad ways, as behavior with task and relationship dimension" (Northouse, 2001, p. 43). Blake and Mouton originally designed the two-dimensional Managerial Grid along the dimensions of concern for people and concern for production. This grid was later renamed the Leadership Grid.

The basic premise for situational leadership theories “ “...is that different situations demand different kinds of leadership" (Northouse, 2001, p. 55). Hershey and Blanchard's (1969) model of situational leadership suggests that there are four leadership styles: (a) delegating, (b) supporting, (c) coaching, and (d) directing. These four styles are on a two-dimensional model with the dimensions of directive behavior and supportive behavior. This theory goes a step further than earlier theories as it takes into account the development of followers.

The situational approach is constructed around the idea that employees move forward and backward along the developmental continuum-a continuum that represents the relative competence and commitment of subordinates. For leaders to be effective, it is essential that they diagnose where subordinates are on the developmental continuum and adapt their leadership styles so they directly match their styles to the development level of subordinates. (Northouse, 2001, p. 59) 
Contingency theory " $\ldots$ is concerned with styles and situations. It provides the framework for effectively matching leader and situation" (Northouse, 2001, p. 76).

Contingency theory represents a shift in leadership research from focusing only on the leader to looking at the leader in conjunction with the situations in which the leader works. It is a leader-match theory with the demands of a situation. (p. 87)

Path-goal theory finds its origin in expectancy theory “....which suggests that subordinates will be motivated if they think they are capable of performing the work, if they believe their efforts will result in certain outcomes, and if they believe the payoffs for doing their work is worthwhile" (Northouse, 2001, p. 89). The focus of path-goal theory is on "...the relationship between the leader's style and the characteristics of the subordinates in a work setting" (p. 123). House began research on this complex theory in 1971 and in 1974 he published a "reformulated" path-goal theory suggesting "...that leaders need to choose a leadership style that best fits the needs of subordinates and the work they are doing" (p. 129).

The transformational leadership approach, developed in the early 1980s, is a process that includes leaders and followers. This approach has been researched extensively by Bass (1985), Bennis and Nanus (1985), Burns (1978), and Tichy and DeVanna (1990). Northouse (2001) stated: “...it is concerned with emotions, values, ethics, standards, and long-term goals, and includes assessing followers' motives, satisfying their needs, and treating them as full human beings" (p. 169).

This brief discussion of leadership theories was designed to provide a framework for the understanding of the progression of leadership from theories that focused on traits to those that focused on behavioral and situational factors, and finally to processes that included leaders and followers. The final leadership theory to be discussed is Leader-Member Exchange theory.

\section{Leader-Member Exchange Theory}

Leader-Member Exchange (LMX) theory finds its origin in the works of Dansereau, Graen, and Haga (1975) and Graen and Cashman (1975), who developed the concept more than 25 years ago. LMX theory focuses on the dyadic relationship between leader and subordinate (follower). This relationship is a process that individualizes the relationship between leader and follower instead of viewing the leadership process as one that is common in nature, that is, the process of applying one leadership style across the board to all followers.

LMX was originally labeled Vertical Dyad Linkage Theory (VDL). This early theory emphasizes the special relationship a leader shares with a subordinate, with each of these relationships being unique and resulting in linkages within the dyads (Northouse, 2001; Yukl, 2002). These linkages take the form of in-groups and out-groups. In-groups are characterized by relationships, and out-groups are characterized by more defined roles (Bass \& Stogdill, 1990; Northouse, 2001; Yukl, 2002).

In-groups are distinguished as those in which members "... are interested in negotiating with the leader what they are willing to do for the group, which often extends beyond their formal job descriptions" (Northouse, 2001, p. 114). This relationship is reciprocal in nature as the leader does more for the subordinate who is part of the in-group and goes the extra mile to assume tasks and duties that are far beyond the scope of the job description. The leader, in exchange for this increased level of work and commitment from the follower, shows the subordinate preference in the assignment of tasks, shares more information, provides increased rewards, and trusts the subordinate enough to delegate, thereby increasing the subordinate's level of responsibility (Bass \& Stogdill, 1990; Northouse, 2001; Yukl, 2002).

Out-groups are made up of followers who prefer a more formal working arrangement with their leader. These employees perform their job according to the letter of their job description. They do not go beyond this performance. The leader requires the subordinate to perform an assigned task for which the subordinate receives his or her salary 
(Yukl, 2002). Dansereau et al. (1975) suggested that out-groups receive less attention than in-groups. Members of the out-group “...just come to work, do their jobs, and go home" (Northouse, 2001, p. 115).

The nature of exchange between leader and follower can be classified according to the quality of exchange, with high quality exchanges resulting in better working relationships. Higher quality exchanges between leader and follower "...produced less employee turnover and more positive performance evaluations" (Northouse, 2001, p. 115). Research by Graen and Uhl-Bien (1995) and Liden, Wayne, and Stilwell (1993) supported this finding. This suggests “...organizations stand to gain much from having leaders who can create good working relationships such as feeling better about themselves and accomplishing more which results in organizational prosperity" (Northouse, 2001, p. $115)$.

Gertsner and Day (1997) conducted a meta-analysis of 25 years of empirical research on LMX theory in which they "...evaluated relationships between LMX and correlates as well as LMX construct and leader-member agreement" (p. 827). They analyzed 164 studies, resulting in 79 studies with 85 independent samples. Their study supported prior research that showed the LMX is positively correlated to greater job satisfaction in subordinates, objective performance, and organizational commitment (Dansereau, Cashman, \& Graen, 1973; Dansereau et al., 1975; Graen \& Cashman, 1985; Graen, Novak, \& Sommerall, 1982). Gertsner and Day's research found “...significant negative correlations between LMX and role conflict and turnover" (p. 835). Gerstner and Day stated "...LMX is generally found to be associated with positive performance-related and attitudinal variables, especially for members" (pp. 828-829). This research supported the premise that leader-member exchange is positively associated with performance at the follower level.

Gertsner and Day (1997) evaluated LMX from a 2-item measurement to a multidimensional scale, specifically looking at the dyadic relationship as the level of analysis. Gertsner and Day suggested that the use of so many different LMX scales in different studies could be the reason for LMX theory discrepancies. Earlier versions of LMX focused on negotiating the latitude a leader allows a follower while later versions focused on the working relationship between leader and follower. Interestingly, Gerstner and Day suggested the LMX “...exchange process is inferred but not directly measured" (p.838). This exchange process is suggestive of the transactional-transformational leadership frame described by Burns (1978) and Bass and Avolio (1994).

Transactional leadership refers to the bulk of leadership models, which focus on exchanges that occur between leaders and their followers. In contrast to transactional leadership, transformational leadership refers to the process whereby an individual engages with others and creates a connection that raises the level of motivation and morality in both leader and the follower. (Northouse, 2001, p.132)

Gerstner and Day (1997) found that LMX includes transactional and transformational processes, a result supported by Graen and Uhl-Bien (1995). LMX relationships are transactional regardless of the quality of exchange. Gerstner and Day (1994) and Graen and Uhl-Bien (1995) suggested that high quality exchanges are not merely transactions between leader and follower but are transformational in nature for both leader and follower. Graen and Uhl-Bien ( 1995) stated "...the mature relationship developed between dyadic members throughout history of exchange results in progressively higher degrees of mutual trust, respect, and obligation within the relationship, persuading followers to engage in more responsible activities than they otherwise would" (p. 232). This research supports leader-member exchange as both a transactional and/or transformational process of exchange.

Gertsner and Day (1997) applied a multilevel and multidomain approach as they evaluated the LMX construct, LMX agreement, and correlates to LMX during 25 years of research. They believed it was essential for long-term research that researchers "....agree on the meaning of LMX, the proper unit of measure (i.e. dyad), and how it should be measured" (p. 840).

This is significant to this study because research suggests: high quality leader-member exchanges produce less employee turnover, more positive performance evaluations, higher frequency of promotions, greater organizational commitment, more desirable work assignments, better job attitudes, more attention and support for the leader, greater 
participation, and faster career progress. (Graen \& Uhl-Bien, 1995; Liden, Wayne, \& Stillwell, 1993, as cited in Northouse, 2001, p. 1150)

Specifically, Graen and Uhl-Bien (1995) suggested that positive outcomes are related to higher quality exchanges between leader and follower:

It is mutual trust, respect, and obligation toward each other which empowers and motivates both to expand beyond the formalized work contract and formalized work roles: to grow out of their prescribed jobs and develop a partnership based on mutual reciprocal influence. (p. 118)

This analysis is vital to the study of leader-member exchange because it addresses the numerous iterations of the LMX as well as the reliability of the instrument. Although Graen and Uhl-Bien (1995) acknowledged the limitations of the LMX-7, they also supported the use of the measure because it had been utilized, in some version, for the past 25 years.

Graen, Liden, and Hoels' (1982) used the LMX to predict employee turnover in a study of 20 systems analysts and programmers from a large public utility. Study results confirmed earlier findings by Dansereau et al. (1973) and Katerberg and Holm (1981) that showed the LMX could be used as an indicator of employee turnover.

In contrast, Vecchio, Griffeth, and Hom's (1986) study of 192 hospital employees found that the LMX was not a strong predictor of employee turnover. "Specifically, the study considered the predictive utility of the VDL (LMX) approach for the outcome variables of employee effect (general and faceted) and turnover." (p. 618) In particular, Vecchio et al. questioned Graen, Liden, and Hoels' (1982) findings based on their study's small sample size. Interestingly, the Vecchio et al. (1986) “...study failed to find LMX as a strong predictor of turnover however the results should be cautiously interpreted as data on unit membership was not obtained.

In addition to the considerable amount of research supporting LMX theory, Northouse (2001) stated three additional strengths of this theory. LMX theory "...makes sense intuitively as it describes work units in terms of those who contribute a bare minimum and those who contribute to an organization" (p. 119). Individuals who have worked in organizations may have experienced the in-group/out-group phenomenon. LMX supports the notion that those who give more will receive more, and those who give less will receive less. LMX theory supports the importance of communication in the leader-follower relationship. "Effective leadership occurs when the communication of leaders and followers (subordinates) is characterized by mutual trust, respect, and commitment" (Northouse, 2001, p. 119). Effective communication is an essential component of high quality dyadic exchanges.

Lastly, LMX theory is the "...only leadership approach that makes the concept of the dyadic relationship the centerpiece of the leadership process" (p. 119). Although Northouse provided some of the strengths of LMX theory, Yukl (2002) said that in order "...to maintain these relationships, the leader must provide attention to the subordinates, remain responsive to their needs and feelings, and rely more on time consuming influence methods such as persuasion and consultation" (p. 117). Yukl (2002) warned that leaders of in-group members must not engage in "... coercions or heavy-handed use of authority without endangering the special relationship" (p. 117).

LMX theory is not without criticism; Northouse (2001) noted three in particular. The LMX concept of ingroups and out-groups may be perceived to be unfair to those members of the out-group. Although LMX does not seek the creation of inequitable work groups, the resulting in-groups and out-groups are not consistent with the traditional concept of leadership. Secondly, Northouse said that LMX theory lacks full development. Although researchers advocate that high quality exchanges should be created, they do not recommend how to create them. The final criticism offered by Northouse surrounded the measurement of the leader-follower exchanges. The numerous iterations of the LMX bring into question the comparability of results obtained from different test versions.

Northouse questioned the development of LMX theory as well as the measurement of leader-member exchanges. LMX theory has undergone many revisions over the years. Although version 7 is most widely used, other versions exist. This makes it difficult for researchers to draw solid conclusions about LMX utility. Graen and Uhl- 
Bien (1995) and Yukl (2002) also believed this to be a problem with LMX theory. The multiple revisions of the LMX bring into question the validity of study results, which remains a limitation to date.

LMX theory, even with its criticisms, has survived for more than 25 years. Graen and Uhl-Bien (1995) discussed the many revisions of LMX theory in their article chronicling the development of LMX theory. They pointed out that these numerous revisions continue to be a point of interest and concern of contemporary researchers. LMX theory emphasizes the relationship between leader and follower, suggesting that higher quality relationships may lead to more positive organizational outcomes. LMX theory encourages leaders to treat followers as individuals, advocating that leaders "...recognize that each employee is unique and wants to relate to us in a special way" (Northouse, 2001, p. 122). The following sections review related research on the relationship between leader-member exchange and age, gender, education, and organizational tenure.

\section{Leader-Member Exchange Theory And Gender}

A review of the literature on LMX and gender yielded one study. Hill (1997) studied the effect of gender and sex-role stereotypes on the quality of leader-member exchange. In her study of 100 military hospital personnel, Hill focused on "...how a member's attitude toward women as managers is related to the quality of the LMX with a female leader" (p. 1). Study results suggested that female managers have a more positive attitude toward women as managers than do their male counterparts, leading to a higher quality of exchange between female leaders and female members. Higher quality exchanges also were found between male leaders and male members.

The lack of research in the area of LMX and gender suggests the need for further research on this topic. With only one study on the topic of leader-member exchange and gender, drawing any real conclusions is premature. This study supports the need for more research in the area of leader-member exchange and gender.

\section{Leader-Member Exchange Theory And Age, Education, And Organizational Tenure}

A review of the literature on the topics of leader-member exchange and age, leader-member exchange and education, and leader-member exchange and organizational tenure did not yield any studies. The lack of published research on the topics of leader-member exchange and age, education, and organizational tenure suggests that although these constructs have been studied they have not been studied in great detail. This suggests that investigators may have attempted to study the constructs together and found no significant relationship or that this area is open for future research. Additionally, the lack of research may be the result of demographic data collection.

Liden and Graen (1980) addressed the issue of collecting data on structural and demographic data, indicating such information is used to analyze, measure, and detect differences between manager and subordinate. Although they found "... significant differences between manger and foreman (subordinate) on age, education, and professionalism," (p. 459) these results were not discussed in detail. According to Liden, Wayne, and Stilwell (1993), “...LMX individual-demographic effects have been dismissed" (p. 664). Their study of newly formed dyads at two major universities hypothesized that "...demographic similarity would have a positive influence on LMX from both the leader's and members' view" (p. 664). Study results indicated no support for demographic similarity. Gertsner and Day (1997) reported "...there appears to be little theoretical or empirical justification for the development of LMX based on simple demographics" (p. 837). Study after study collected demographic information, and with the exception of one study on gender, researchers have not reported their findings to be significant. This lack of theoretical or empirical data on the demographic variables of age, education, and organization tenure suggests the need for further research in these areas.

A review of literature on the topic of leader-member exchange and age, gender, education, and organizational tenure suggest the lack of empirical research on the topic. This literature review has presented a theoretical framework that can be used to understand leader-member exchange and age, gender, education, and organizational tenure. 


\section{METHODOLOGY}

This study used a quantitative approach to examine the relationship between the Leader-Member Exchange and the demographic variables of age, gender, education and organizational tenure. This study employed the use of the LMX-7 to test hypotheses via the collection of survey data.

\section{Participants}

Participants in this study included 143 employees of an international company specializing in fire protection, alarm detection, integrated security, and health care communications. Although the company has offices in the United States, Canada, and Mexico, this study focused on employees from offices located in the United States. Participant job titles included office administrator, human resource manager, accounts receivable champion, total service manager, and general manager. Each of these staff members received a letter from the investigator inviting participation in the study. The letter to potential participants included the purpose of the study, requested their voluntary participation, and assured all participants of the confidentiality of their responses.

\section{Measures}

The quality of dyadic relationship between leader and follower was measured using the LMX-7 by Green and Uhl-Bien (1995). The measure consists of seven questions rated on a 5-point Likert scale. Anchors in the 1-point range include Rarely, Not a bit, None, Strongly disagree, and Extremely ineffective. Anchors in the 5-point scale include Very often, A great deal, Fully, Very high, Strongly agree, and Extremely effective. Anchors on the seven items vary. Individual LMX-7 scores were obtained by summing the responses to each item. Score sums that fell between 30 and 35 are considered very high, 25-29 are high, 20-24 are moderate, 15-19 are low and 7-14 are very low. "Scores in the upper ranges are indicative of stronger, higher quality leader member exchanges (e.g. in-group members) whereas scores in the lower ranges are indicative of exchanges of lesser quality (e.g., out-group members)" (Northouse, 2001, p. 127). Researchers of leader-member exchange remain at odds as to what LMX is or how it should be measured; this is evidenced by the many iterations of this instrument. Despite research controversy on what LMX is and how it should be measured, the LMX-7 remains the most consistently used measure of Leader-Member Exchange.

\section{Results}

The purpose of this study was the exploration of the relationship between LMX and demographic variables: age, gender, education, and organizational tenure. This research used a quantitative approach. Data were collected through the use of Leader-Member Exchange-Version 7 (LMX-7). This chapter presents the data and results of this quantitative research, specifically addressing the research question presented in the introduction. The research question was restated as a series of hypotheses to address the multiple variables, relationships, and indicators relative to quality of the dyadic relationship between leader and follower. A synopsis of the research finding is presented in Tables $1-3$. Table 1 represents the null hypothesis results. Table 2 represents the number and percent of participants by gender and by leader and follower. Table 3 represents the number and percentage of participants' educational level by leader and follower.

Six hundred and fifty four surveys were mailed; of the 192 surveys returned, 10 came back without demographic sheets and 39 were from respondents who had more than one job title. The resulting 143 valid survey responses represented a survey response rate of $23.63 \%$. Thirty-one participants completed the leader-survey version and 112 participants completed the follower-survey version of LMX-7.This is illustrated in Figure 1. All statistical calculations are based upon the return rate, not the total sample size.

The participants ranged from 20 years of age to more than 60 years of age. Although all 31 participants who completed the leader survey responded to the study's age question, four of the 112 participants who completed the follower survey chose not to respond to the age question. This represents $6.3 \%$ of the 143 participants. Of those participants age 29 or younger, none completed the leader survey while 15 respondents completed the follower 
survey; combined this represents $10 \%$ of respondents whose age range was 29 years or younger. Of respondents age $30-39$, five completed the leader survey and 30 completed the follower survey; combined this represents $25 \%$ of participants age 30-39 years. Of respondents age 40-49, 14 participants completed the leader survey and 38 completed the follower survey; combined this represents $38 \%$ of participants age $40-49$ years. Of respondents age 50 or older, 12 completed the leader survey and 25 completed the follower survey; combined this represents $27 \%$ of participants age 50 years or older. Figure 3 graphically displays the breakdown of age groups by leader and follower survey participant.

Table 1

$\mathrm{H}_{0}$ : There Is No Relationship Between The Quality Of Dyadic Relationship Between Leader And Follower And Age, Gender, Education, And Organizational Tenure.

\begin{tabular}{|c|c|c|c|}
\hline Hypotheses & $\chi^{2}$ & p value & Conclusion \\
\hline $\begin{array}{l}\text { Age is independent of the quality of dyadic relationship between } \\
\text { leader and follower. }\end{array}$ & 21.360 & .26 & Fail to Reject \\
\hline $\begin{array}{l}\text { Age is independent of the quality of dyadic relationship between } \\
\text { leader and follower at the leader level. }\end{array}$ & 7.645 & .11 & Fail to Reject \\
\hline $\begin{array}{l}\text { Age is independent of the quality of dyadic relationship between } \\
\text { leader and follower at the follower level. }\end{array}$ & 15.400 & .63 & Fail to Reject \\
\hline $\begin{array}{l}\text { Gender is independent of the quality of dyadic relationship between } \\
\text { leader and follower. }\end{array}$ & 7.577 & .06 & Fail to Reject \\
\hline $\begin{array}{l}\text { Gender is independent of the quality of dyadic relationship between } \\
\text { leader and follower at the leader level. }\end{array}$ & 2.971 & 23 & Fail to Reject \\
\hline $\begin{array}{l}\text { Gender is independent of the quality of dyadic relationship between } \\
\text { leader and follower at the follower level. }\end{array}$ & 3.596 & .31 & Fail to Reject \\
\hline $\begin{array}{l}\text { Education is independent of the quality of dyadic relationship } \\
\text { between leader and follower. }\end{array}$ & 14.938 & .46 & Fail to Reject \\
\hline $\begin{array}{l}\text { Education is independent of the quality of dyadic relationship } \\
\text { between leader and follower at the leader level. }\end{array}$ & 5.325 & .26 & Fail to Reject \\
\hline $\begin{array}{l}\text { Education is independent of the quality of dyadic relationship } \\
\text { between leader and follower at the follower level. }\end{array}$ & 15.922 & $01 * *$ & Reject \\
\hline $\begin{array}{l}\text { Organizational tenure is independent of the quality of dyadic } \\
\text { relationship between leader and follower. }\end{array}$ & .876 & .99 & Fail to Reject \\
\hline $\begin{array}{l}\text { Organizational tenure is independent of the quality of dyadic } \\
\text { relationship between leader and follower at the leader level. }\end{array}$ & 6.596 & .16 & Fail to Reject \\
\hline $\begin{array}{l}\text { Organizational tenure is independent of the quality of dyadic } \\
\text { relationship between leader and follower. }\end{array}$ & 5.505 & 48 & Fail to Reject \\
\hline
\end{tabular}

$N=143$; *Significant at the $p<.05$ level; **Highly Significant at the $p<.01$ level

Figure 1: Survey Responses

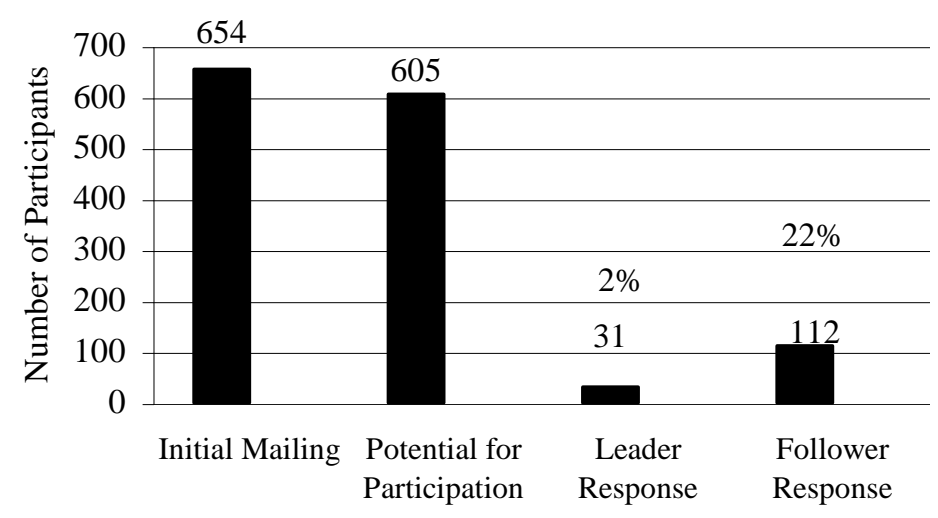

Responses 
Figure 2: Participants By Age By Leader And Follower

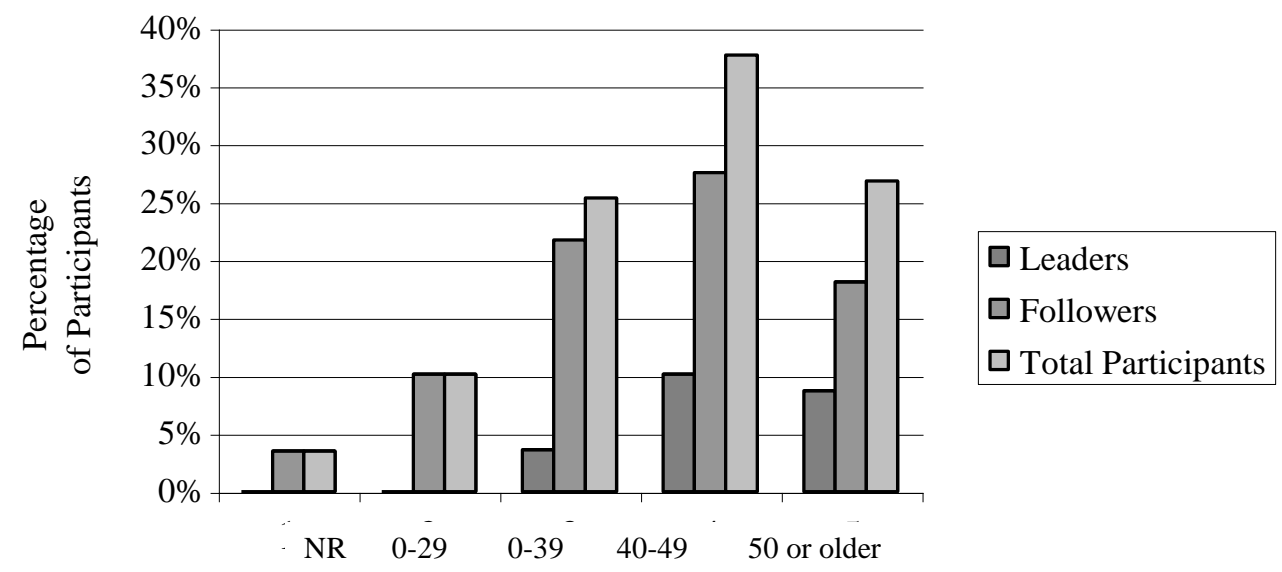

Seventy-five participants were male, representing $52.45 \%$ of the sample, and 68 participants were female, representing $47.55 \%$ of the sample. Thirty of the male participants took the leader survey, and 45 of the male participants took the follower survey. Only one of the participants responding to the leader survey was female, and 67 of the follower survey respondents were female. This is reported in Table 2.

Table 2

Number And Percent Of Participants By Gender By Leader And Follower

\begin{tabular}{|c|c|c|c|}
\hline & Male & Female & Total \\
\hline Leaders & 30 & 1 & 31 \\
\hline & $96.77 \%$ & $3.23 \%$ & $100 \%$ \\
\hline Followers & 45 & 67 & 112 \\
\hline
\end{tabular}

The eight educational levels surveyed included Some High School, High School Completed or GED, Some College, Bachelor's Degree, Some Graduate Work, Master's Degree, Some Post-Graduate Work, and Post-graduate Degree. The data were collapsed, resulting in three levels of education: (a) High School/GED; (b) Some College; and (c) Bachelor's Degree or More. The survey results indicated that for those who participated in the leader survey, $6.45 \%$ attained an educational level of High School or GED; $48.39 \%$ attained an educational level of Some College; and $45.16 \%$ attained an educational level of Bachelor's Degree or More. For the follower participants, the survey results indicated that $26.78 \%$ attained an educational level of High School or GED; $49.11 \%$ attained an educational level of Some College; and the remaining 24.11\% attained an educational level of Bachelor's Degree or More. Table 3 illustrates the breakdown into the leader and follower groups.

Table 3

Number And Percent Of Participants' Educational Level By Leader And Follower

\begin{tabular}{|c|c|c|c|c|}
\hline & High School/GED & Some College & Bachelor's or More & Total \\
\hline Leaders & 2 & 15 & 14 & 31 \\
\hline Followers & $6.45 \%$ & $48.39 \%$ & $45.16 \%$ & $100 \%$ \\
\hline & 30 & 55 & 27 & 112 \\
\hline
\end{tabular}


One hundred and thirty-four of the participants reported organizational tenure in at least one of 11 categories; nine participants, all followers, chose not to report organizational tenure. The original 11 categories included Less than 1 year, 1-5 years, 6-19 years, 11-15 years, 16-20 years, $21-25$ years, 26-30 years, $31-35$ years, 36- 40 years, 41 years or more, and NR for No Response. The data were collapsed into three categories, designated as follows: (a) 0-5 Years; (b) 6-15 years; and (c) 16 or more years. Total sample results indicated that $23.13 \%$ of the participants were leaders and $76.86 \%$ were followers.

Within each category of organizational tenure, $40.30 \%$ were in the $0-5$ years category, $28.36 \%$ of the participants were in the 6-15 year category, and $31.34 \%$ of the participants were in the 16 years or more category of organizational tenure. Of the 31 participants in the leader category, $16.13 \%$ participants were in the $0-5$ years category of organizational tenure, $22.58 \%$ were in the 6-15 years category, and $61.29 \%$ were in the 16 years or more categories. This certainly contrasts with the data received for followers and organizational tenure. Data analysis indicates that $47.57 \%$ of followers were in the $0-5$ years category of organizational tenure, while $30.10 \%$ of followers were in the 6-15 years category, with the remaining $22.33 \%$ of followers falling into the 16 or more years category. Figure 3 illustrates the breakdown of organizational tenure by leader/follower categories.

Figure 3: Organizational Tenure By Leader And Follower

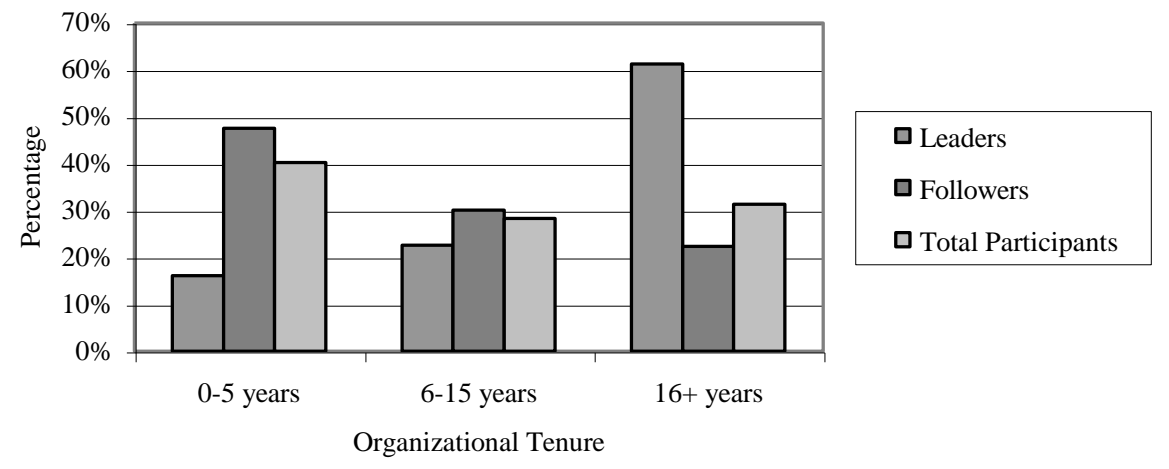

As demonstrated in Table 1, the Null Hypothesis was disaggregated into 12 separate hypotheses. Of the 12 hypotheses, one was rejected as follows: $H_{9}$ : Education is independent of the quality of dyadic relationship between leader and follower at the follower level. A Chi-Square test of independence was conducted to examine the relationship between leader-member exchange and educational level at the follower level. The Chi-Square Test for independence resulted in $p=.01$, which is less than the confidence level of .05 , the result of which is to reject the hypothesis. Cross-tabulation between LMX-7 and education, at the follower level, resulted in a Chi-Square value of 15.922 with 6 degrees of freedom and, .01 significance for the 112 cases evaluated. This demonstrates statistical dependence, the implication of which organizational tenure is associated with leader member exchange at the follower level. Results are demonstrated in Figure 4. This relationship is discussed in Chapter 5.

\section{Discussion}

The purpose of this study was to investigate the relationship between the quality of dyadic relationship between leader and follower and age, gender, education and organizational tenure. The null hypothesis was disaggregated into 12 individual hypotheses, in which each demographic variable was tested with LMX, with LMX at the leader level, and with LMX at the follower level. Only one demonstrated a significant relationship: LMX and education at the follower level. The remaining demographic variables tested-age; gender; education and LMX and education and LMX at the leader level; and organizational tenure - did not demonstrate a significant relationship. 
Figure 4: Leader-Member Exchange By Education At The Follower Level

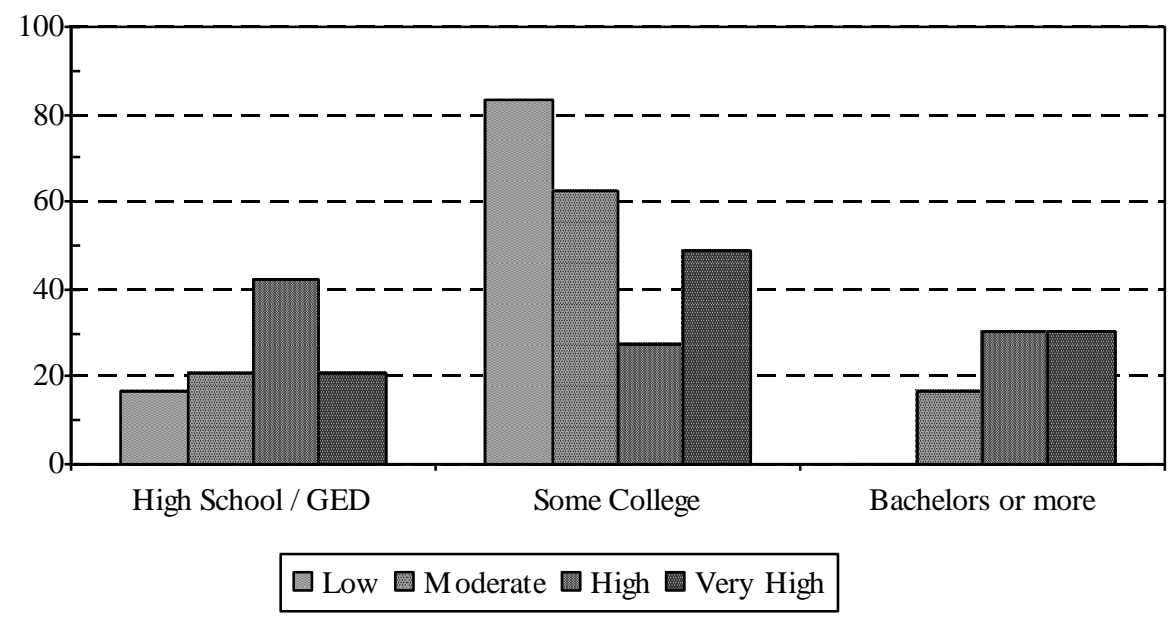

A review of the literature on the topics of leader-member exchange and age did not yield any studies that specifically addressed these constructs suggesting that either no relationship was found in previous research or this area of research is in need of additional research.

A review of the literature on LMX and gender yielded only one study by Hill (1997) who examined the effect of gender and sex-role stereotypes on the quality of leader-member exchange. Study results suggested that female managers have a more positive attitude toward women as managers than do their male counterparts, leading to a higher quality of exchange between female leaders and female members. Higher quality exchanges also were found between male leaders and male members.

The lack of research in the area of LMX and gender suggests the need for further research on this topic. With only one study on the topic of leader-member exchange and gender, drawing any real conclusions is premature supporting the need for more research in the area of leader-member exchange and gender.

A review of the literature on the topics of leader-member exchange and education did not yield any studies however; findings of this research study suggest a greater percentage of followers (46.7\%) with a High School/GED level education view their leaders as being High in leader-member exchange. The vast majority of followers $(83.3 \%)$ with Some College viewed their leaders a being Low in leader-member exchange while some (62.5\%) viewed their leaders as being Moderate in leader-member exchange. Followers with a Bachelors or more viewed their leaders as being evenly divided between High and Very High in leader-member exchange. Interestingly those followers with a Bachelors or more did not categorize any of their leaders as being Low in leader-member exchange.

The research findings suggest that followers with High School/GED have a High quality of leader-member exchange, followers with Some College have a Low to Moderate quality of leader-member exchange, and followers who have a Bachelors or more have a High to Very High quality of leader-member exchange. One possible explanation for these findings is those followers with minimal education, High School/GED, may view their leaders as more knowledgeable, deferring to their leadership skill, believing that because of the established relationship of leader and follower, the leader clearly knows best, with the follower not questioning leadership authority. As followers gain Some College, they gain just enough knowledge to believe they know more than their leader and score their leader as having a Low quality of leader-member exchange. Finally, as followers gain more education, Bachelors or more, they have matured and developed critical thinking skills as well as respect for the relationship with their leader. This allows followers to evaluate leader-member exchanges from a more mature viewpoint resulting in a High to Very High quality of leader-member exchange. 
The educational implications for these findings suggest organizations should support increased formal academic programs that foster higher quality exchanges. From a pure industry perspective, leaders who know those followers who have Some College may hold a viewpoint that suggests lower quality relationships between leader and follower, by virtue of the follower's academic status, may wish to work harder at developing better relationships more characteristic of in-groups.

Liden and Graen (1980) addressed the issue of collecting data on structural and demographic data, indicating such information is used to analyze, measure, and detect differences between manager and subordinate. Although they found "... significant differences between manger and foreman (subordinate) on age, education, and professionalism," (p. 459) these results were not discussed in detail. According to Liden, Wayne, and Stilwell (1993), "...LMX individual-demographic effects have been dismissed" (p. 664). Their study of newly formed dyads at two major universities hypothesized that "...demographic similarity would have a positive influence on LMX from both the leader's and members' view” (p. 664). Study results indicated no support for demographic similarity.

Gertsner and Day (1997) reported “...there appears to be little theoretical or empirical justification for the development of LMX based on simple demographics" (p. 837). Study after study collected demographic information, and with the exception of one study on gender, researchers have not reported their findings to be significant. This lack of theoretical or empirical data on demographic variables such as age, education, and organizational tenure suggests the need for further research in these areas.

\section{LIMITATIONS}

The generalization of these study findings is a limitation of this research. This study was limited to one United States company. The researcher selected the sample population, thereby limiting the sample.

Due to the nature of the study questions, asking subordinates to discuss their superiors, some respondents may not have answered honestly due to fear of reprisal. This may have also limited the number of actual responses. While a response rate of $23 \%$ was achieved, a higher response rate would have been desirable. Of the total number of responses, 143, only 31 were leaders. This may have had an effect on key study findings as no significance was found for any of the research questions at the leader level.

Throughout this study, the terms job satisfaction and organizational effectiveness are used by this and other researchers; however, they were not operationalized for the purpose of this study.

The concept of immediacy may have affected research findings as it is the tendency of participants to score a survey based on their most recent memory. If the followers' most recent contact with their leader resulted in a positive outcome, the participant may unknowingly respond to survey questions based on the immediacy of the event. This would apply the same for leaders as well.

\section{RECOMMENDATIONS FOR FUTURE RESEARCH}

Future research needs to be conducted on the relationship between leader and follower and as suggested by Graen and Uhl-Bein (1995) “ ... be both descriptive and prescriptive” (p. 239). Future research should look at different levels in the organization. This study focused on the general managers as leaders, and office administrators, human resource managers, accounts receivable champions, and total service managers as followers. Organizations have multiple organizational levels in which to explore a leader/follower relationship. Future research might consider exploring more levels within the organization and comparing results across those levels for a better picture of the whole organization. The results of this suggested future research would provide greater opportunities for leaders to understand the framework in which followers operate providing opportunities for both leader and follower to increase organizational outcomes. 
Future research may also include special attention to situational variables that may affect the quality of leader member exchange relationship. "Situational leadership stresses that leadership is composed of both a directive and supportive dimension, and each has to be applied appropriately in a given situation" (Northouse, 2004, p 87).

\section{CONCLUSION}

The purpose of this study was to examine the exploration of the relationship between leader-member exchange and demographic variables: age, gender, education, and organizational tenure. In a broader sense, this study was designed to clarify the reader's thinking about this relationship. This research provides several significant contributions on both a scholarly and practitioner level.

First, leadership and leader-member exchange are both process driven, with leaders, by virtue of their position, having influence over followers. Leader-member exchange is a challenge for contemporary leaders; the results of this study may help leaders deal more effectively with quality of the dyadic exchange between leader and follower resulting in greater organizational effectiveness.

Second, this research adds to a very limited body of research on leader-member exchange and gender. Hill (1997) found that females have a higher quality of exchange with other female managers; the same exists for male managers. This is relevant in industry as it suggests that women working with other women produce higher quality exchanges than women who work for men or vice versa. As a scholar, the implications for future study are enormous in the current dynamic diverse workforce. Too little research exists to draw any conclusions that have practical application, however the need for future research on leader-member exchange and gender is clear. With women having a smaller portion of leadership and management roles, the implication of how well the work with their male counterparts could have an impact or organizational performance.

Third, this research adds to a non-existent body of research on leader-member exchange and education. The industry implications of this study suggest that followers with minimal education may view their leaders as more knowledgeable. As followers gain some education and some knowledge they now believe they know more than their leader however as they proceed along the educational continuum and gain more education, followers have matured and developed critical thinking skills as well as respect for the relationship with their leader. This presents as a higher quality of exchange between leader and follower. The industry implication is knowledge that this is a natural progression of employees through their educational process. The educational implications for these findings suggest organizations should support increased formal academic programs that foster higher quality exchanges.

Fourth, this research adds to a non-existent body of research on leader-member exchange and age. With an aging diverse workforce, the need for research on quality of exchange and age is critical. We are mixing workforces of many generations; we need to know if age has an impact on quality of leader-member exchange. This area is ripe for potential future study.

Finally, this research adds to a non-existent body of research on leader-member exchange and organizational tenure, however study results were unable to support a significant relationship between the two. From an industry perspective, it would be helpful to know if employees with longer organizational tenures have higher quality relationships with their leaders, however without any research to support this, conclusions cannot be drawn. This is an area wide open for future research and with workforce that seems to move to different employers more frequently than employees in the past, research would be helpful at the very least as a strategic human resource planning tool. This research study contributes to a very limited body of knowledge on the construct of leader-member exchange. Research findings clearly support the need for future research that integrates this construct as well as places emphasis on the demographic variables of age, gender, education, and organizational tenure.

\section{REFERENCES}

1. Bass, B. M. (1985). Leadership and performance beyond expectations. New York: Free Press. 
2. Bass, B. M. (1990). Bass \& stogdill's handbook of leadership theory and managerial applications. $3^{\text {rd }}$ edition. New York, NY: The Free Press.

3. Bass, B. M. and Avolio, B. J. (1994). Improving organizational effectiveness through transformational leadership. Thousand Oaks, CA: Sage.

4. $\quad$ Bennis, W. G. and Nanua, B. (1985). Leaders: The strategies for taking charge. New York: Harper\& Row.

5. Blake, R. R. and Mouton, J. S. (1964). The managerial grid. Houston, TX: Gulf Publishing.

6. Brigham, E. F. and Houston, J. F. (2004). Fundamentals of financial management $10^{\text {th }}$ edition. Mason, Ohio: South-Western.

7. $\quad$ Burns, J. M. (1978) Leadership. New York: Harper \& Row.

8. Castro S. L. and Cogliser, C. C. (1999). Leader-member exchange (LMX) research: A comprehensive review of theory, measurement, and data-analytic practices. Leadership Quarterly. Retrieved November 2, 2003 from http://search.epnet.com/direct.asp?an=223794\&db=pbh.

9. Dansereau, F., Cashman, J., and Graen, G. (1973). Instrumentality theory and equity theory as complementary approaches in predicting the relationship of leadership turnover among managers. Organizational Behavior and Human Performance, 10, 184-200.

10. Dansereau F., Graen, G. B., and Haga, W. (1975). A vertical dyad linkage approach to leadership in formal organizations: A longitudinal investigation of the managerial role-making process. Organizational Behavior and Human Performance, 13, 46-78.

11. Gertsner, C. R. and Day D. V. (1997). Meta-analytic review of leader-member exchange theory: Correlates and construct issues. Journal of Applied Psychology, 82(6), 827-844.

12. Graen, G. B. and Cashman, J. F. (1975). A role making model of leadership in formal organizations: A developmental approach. In J. G. Hunt and L. L. Larson (Eds.), Leadership frontiers (p. 143-165). Kent, OH: Kent State University Press.

13. Graen, G. B., Cashman, J. F., Ginsburgh, S., and Schiemann, W. (1977). Effects of linking-pin quality on quality of working life of lower participants. Administrative Science Quarterly, 22, 491-504.

14. Graen, G. B., Liden, R. C., and Hoel, W. (1982). Role of leadership in the employee withdrawal process. Journal of Applied Psychology, 67(6), 868-872.

15. Graen, G. B., Novak, M., and Sommerkamp, P. (1982). The effects of leader-member exchange and job design on productivity and satisfaction: Testing a dual attachment model. Organizational Behavior and Human Performance, 30, 109-131.

16. Graen, G. B. and Scandura, T. (1987). Toward a psychology of dyadic organizing. Research in Organizational Behavior, 9, 175-208.

17. Graen, G. B. and Uhl-Bien, M. (1991). The transformation of work group professionals into self-managing and partially self-designing contributors: Toward a theory of leadership-making. Journal of Management Systems, 3(3), 33-48.

18. Graen, G. B. and Uhl-Bien, M. (1995). Relationship-based approach to leadership: Development of leadermember exchange (LMX) theory of leadership over 25 years: Applying a multilevel multi-domain approach. Leadership Quarterly, 6, 219-247.

19. Hersey, P. and Blanchard, K. H. (1974). So you want to know your leadership style. Training and Development Journal, 28, 22-37.

20. Hill, C. L. (1997). The effect of gender and sex-role stereotypes on leader-member exchange relations and upward influence tactics. Dissertation Abstracts International, 58 (08B), 4501. (UMI No. 9804364).

21. Liden, R. C. and Graen, G. (1980). Generalizability of the vertical dyad linkage model of leadership. Academy of Management Journal, 23(3), 451-465.

22. Liden, R. C., Wayne, S. J., and Stilwell, D., (1993). A longitudinal study on the early development of leadermember exchanges. Journal of Applied Psychology, 78(4), 662-674.

23. Lussier, R. N. (2003). Management fundamentals: Concepts, applications, skill development $\left(2^{\text {nd }}\right.$ ed.). Mason, OH: South-Western.

24. Northouse, P. G. (2001). Leadership theory and practice. (2nd ed.). Thousand Oaks, CA: Sage Publications.

25. Tichy, N. M. and DeVanna, M. A. (1990). The transformational leader $\left(2^{\text {nd }}\right.$ ed.) New York: John Wiley.

26. Vecchio, R. P., Griffeth, R. W., and Hom, P. W. (1986). The predictive utility of the vertical dyad linkage approach. The Journal of Social Psychology, 126(5), 617-625.

27. Yukl, G. (2002). Leadership in organizations (5th ed.). Upper Saddle River, NJ: Prentice Hall. 